\title{
Correction to: Percutaneous ozone nucleolysis for lumbar disc herniation
}

\author{
Mohamed Ezeldin ${ }^{1,2} \cdot$ Marco Leonardi ${ }^{2,3} \cdot$ Ciro Princiotta $^{2} \cdot$ Massimo Dall'olio $^{2} \cdot$ Mohammed Tharwat $^{1}$. \\ Mohammed Zaki ${ }^{1}$ Mohamed E. Abdel-Wanis ${ }^{4}$ - Luigi Cirillo ${ }^{2,3}$
}

Published online: 11 July 2019

(C) Springer-Verlag GmbH Germany, part of Springer Nature 2019

\section{Correction to: Neuroradiology (2018) 60:1231-1241 \\ https://doi.org/10.1007/s00234-018-2083-4}

The published version of this article unfortunately contained a mistake. Affiliation 2 was presented incorrectly in the original article. The updated affiliation is Neuroradiology Unit, Bellaria Hospital, IRCCS Institute of Neurological Sciences, Bologna, Italy.

Publisher's note Springer Nature remains neutral with regard to jurisdictional claims in published maps and institutional affiliations.

The online version of the original article can be found at https://doi.org/ 10.1007/s00234-018-2083-4

Mohamed Ezeldin

Dr.muhammedezz@gmail.com;

Dr.mohamedezeldin@med.sohag.edu.eg

1 Department of Diagnostic and Interventional Radiology, Faculty of Medicine, Sohag University, Sohag, Egypt

2 Neuroradiology Unit, Bellaria Hospital, IRCCS Institute of Neurological Sciences, Bologna, Italy

3 DIMES, Department of Specialty, Diagnostic and Experimental Medicine, University of Bologna, Bologna, Italy

4 Department of Orthopaedic Surgery, Faculty of Medicine, Sohag University, Sohag, Egypt 